\title{
ОСОБЕННОСТИ РЕФЛЕКСИВНОСТИ СТУДЕНТОВ БАКАЛАВРИАТА ПЕДАГОГИЧЕСКОГО ПРОФИЛЯ
}

\section{PECULIARITIES OF REFLEXIVITY AMONG BACHELOR'S DEGREE STUDENTS OF A PEDAGOGICAL SPECIALTY}

\section{Burykina}

Summary: The article presents the results of the study of reflexivity of students of pedagogical profile. The obtained data are important for the organization of educational activities of students. Analysis and selfanalysis of the manifestations and nature of students ' reflexivity will have a positive impact on the quality of mastering professional skills.

Keywords: reflexivity, reflection, reflexivity by the criterion of orientation to the object, reflexivity by the criterion of temporal orientation, reflection by the criterion of orientation of consciousness.
$\mathrm{B}$ основе новой парадигмы высшего образования лежит идея развития личности студентов и обучения их навыкам профессиональной мобильности и успешности в условиях быстро меняющегося рынка труда. Особую значимость приобретает рефлексивность, обеспечивающая студентам возможность осмысливать собственные действия, оценивать результаты, определять учебные цели и смысложизненные ориентации, корректировать свой образовательный путь.

Теоретико-методологическое основание исследования рефлексивности как процесса, состояния, свойства, качества личности составили дифференциальная модель рефлексии (Д.А. Леонтьев), позволяющая разграничить позитивные и негативные эффекты рефлексии; метакогнитивный подход к рассмотрению рефлексии (А.В. Карпов, В.В. Пономарева) как регулятора, позволяющего понять собственное состояние.

Рефлексивность студентов интересует многих исследователей (И.В. Абакумова, К.А. Бабиянц, М.Е. Валиуллина, А.М. Двойнин, Г.И. Данилова, С.А. Дюпина, И.Н. Зиник, А.В. Карпов, О.В. Каратеев, А.В. Ляшук, Б. Мессер, С.А. Пеняева, Л.А. Рассудова и другие) в связи с различными аспектами их жизнедеятельности и личностными образованиями. В значительной части исследований представляются эмпирические характеристики студентов с разным уровнем рефлексивности. Остановимся на некоторых из них.

Высокорефлексивных студентов характеризует, по мнению О.В. Каратеева, их объем и глубина саморас-
Бурыкина Марина Юрьевна,

Д.псх.н., профрессор, Брянский государственный университет имени академика И.Г. Петровского mabur03@yandex.ru

Аннотация: В статье представлены результаты исследования рефлексивности студентов педагогического профиля. Полученные данные имеют значение для организации учебной деятельности студентов. Анализ и самоанализ проявлений и характера рефлексивности студентов будет благоприятно сказываться на качестве освоения профессиональных умений.

Ключевые слова: рефлексивность, рефлексия, рефлексивность по критерию направленности на объект, рефлексивность по критерию временной направленности, рефлексия по критерию направленности сознания.

крытия, креативность, повышенная тревожность, дипломатичность, сила Я, самодостаточность, в общении - проницательность и рассудительность, вовлеченность в ситуацию общения [6]. А.В. Карпов выделяет когнитивную особенность высокорефлексивных личностей. Принимая решения, они стремятся использовать как внешнюю, так и внутреннюю информацию, усложняют ситуацию выбора путем нахождения альтернативы, с которой трудно расстаются в отличии от низкорефлексивных студентов [7]. И.Н. Зиник отмечает, что высокорефлексивные студенты напористы в отстаивании собственных интересов. В межличностных отношениях чаще выстраивают доминирующее поведение и не используют стратегии подчинения. Однако, чем разнообразнее стили поведения, тем более социально адаптирован человек [5].А.В. Ляшук представляет результаты, демонстрирующие то, что при высокой рефлексивности наблюдается безопасность от «ментальных вирусов», и в отличие от студентов со средним уровнем рефлексивности, наименьшая подверженность информационно-психологическому воздействию [10].

Г.С. Пеньякова вслед за Б. Мессер указывает, что у высокорефлексивных студентов обнаруживаются высокие показатели учебной успеваемости, Они более успешны в плане решения интеллектуальных задач [12]. Эти данные подтверждаются С.А. Дюпиной в том, что студенты, обладающие быстрыми/точными и рефлексивными когнитивными стилями, быстро перерабатывают усложненный учебный материал. При этом они обнаруживают быстрое включение операционных механизмов в процесс запоминания путем использования механизмов 
схематизации и структурирования [3]. По мнению А.К. Самойличенко, А.А. Токмаковой эти студенты отличаются постоянством интересов, тщательностью подготовки учебных заданий [13].

А.И. Санников высокорефлексивных студентов описывает как задумывающихся над происходящим, над причинно-следственными связями относительно собственных действий и поступков других людей; планирующих свою деятельность; рассматривающих варианты решений. Они обладают способностью продумывать условия достижения цели, выстраивать адекватную программу действий, соответственную планам деятельности, анализировать свои поступки, психологической устойчивостью, эмоциональной выдержанностью, хорошей адаптированностью к социальной микросреде [14].

В то же время в исследовании А.И. Санникова показано, что люди с высоким уровнем рефлексивности в ситуации принятия решения не только способны четко и глубоко анализировать свои поступки, но и отличаются психологической устойчивостью, отсутствием тревожности, эмоциональной выдержанностью, хорошей адаптированностью к социальной микросреде [14].

Кроме того, существуют данные Прохорова А.О., Чернова А.В., свидетельствующие о том, что в напряженных ситуациях (в частности, в ситуации экзамена) низкорефлексивные индивиды склонны испытывать состояния высокой интенсивности - волнение и тревогу, а высокорефлексивные - эмоциональные состояния низкой интенсивности, такие как подавленность или грусть [11, 17]. Волканевский С.В. доказывает, что рефлексивность может рассматриваться как детерминанта синдрома «психического выгорания» личности [2].

Н.О. Амосова определяет рефлексивные механизмы сохранения психологического здоровья студентов разного возраста при конструктивной и неконструктивной рефлексии личности, позволяющей им положительно «самоизменяться», самостоятельно справляться с кризисной ситуацией благодаря конструктивной рефлексии, преобразующей себя. Однако «самокопание» в собственных проблемах способствует «застреванию» на кризисном состоянии, сопровождающееся уходом «в себя», от контакта с окружающим миром, депрессивными тенденциями, отказом от конструктивного разрешения кризиса. Высокая рефлексивность может иметь негативные черты, направленные на саморазрушение психического здоровья (неконструктивная рефлексия). По мнению В. Франкла «гиперрефлексия» сходна с гиперинтенцией в том, что порождает невроз [1].

Низкорефлексивные студенты отличаются эмоциональной сензитивностью, социальной смелостью, экстравертированностью, развитым самоконтролем, чувствительностью в общении, смелостью и общительностью в сочетании со стремлением контролировать ситуацию общения. Эти характеристики по данным О.В. Каратеева способствуют самораскрытию, но страх перед его последствиями, сокращает проявления самораскрытия и увеличивает его глубину [6].

Низкорефлексивные студенты склонны к упрощению ситуации (А.В. Карпов), В конфликте они отличаются малой активностью и низкой кооперацией, занимают пассивную позицию (И.Н. Зиник). Импульсивные, медленно/неточного когнитивных стилей студенты медленно осваивают учебный усложненный материал, включают операционные механизмы запоминания, предпочитают группировать, перекодировать и достраивать предложенную информацию (С.А. Дюпина).

Рассматривая рефлексивность как регулятор учебнопознавательной и когнитивно-мотивационной сферы деятельности, А.К. Самойличенко, А.А. Токмакова отмечают, что низкорефлексивные студенты, склонные к импульсивным действиям, часто принимают необдуманные решения, меняют цели, интересы. Они стремятся к получению быстрого результата, нуждаются во внешнем контроле, так как обладают слабостью самоконтроля, что является предикторами низкого уровня академической успеваемости [13].

По данным А.И. Санникова импульсивные студенты с трудом справляются с задачами на решение проблем без указания альтернативных ответов. Лица с низким уровнем рефлексивности характеризуются автором как уверенные в себе, независимые в поведении, но подверженные совершению неосторожных, необдуманных поступков, как неуравновешенные. При принятии решений, в жестких временных ограничениях, они могут проявлять импульсивные действия, менять настроение и выражать спонтанную агрессию [14].

У низкорефлексивных студентов, отмечает Н.О. Амосова, наблюдается непродуктивное протекание личностной рефлексии в связи с отсутствием схемы процедуры, программы, алгоритма ориентировочной основы рефлексивной деятельности, порядка выполнения мыслительных операций [1].

О.В. Филатова рассматривает рефлексивность как детерминанту деятельности исполнительского типа. Автор доказательно показывает, что между уровнем рефлексивности и эффективности деятельности исполнительского типа существует устойчивая закономерная связь. В группе низкорефлексивных исполнителей отмечаются низкие показатели эффективности деятельности. При повышенной степени рефлексивности исполнители предпочитают более мягкие стили управления [16]. 
В ряде исследований показано, что повышенная тревожность выступает как одна из базовых характеристик высокорефлексивной личности. По данным М.В. Семенихиной, Высокая личностная тревожность характерна как для мужчин, так и для женщин, имеющих высокий уровень рефлексии. При этом нерефлексивные личности, независимо от пола, а также мужчины со средним - оптимальным уровнем рефлексии имеют умеренную тревожность [15].

В исследовании Н.М. Голубевой рефлексия рассматривается исходным инструментом изменения личности, путем связывания мышления с реальностью, тем самым детерминируя адаптационные феномены. Свое внимание автор концентрирует на адаптивной и дезадаптивной функциях рефлексии. Рефлексия способствует психологической адаптированности студентов, необходимой для оперативного реагирования на изменения ситуации, для осознания стабильности и четкости рефлексивных образов. Побуждение к рефлексии извне тормозит адаптационный процесс из-за избыточной насыщенности рефлексивных образов. Недостаточно высокий уровень владения студентами адаптивными формами рефлексии требует обучения использованию рефлексивных приемов и навыков в субъективно новых и трудных ситуациях [4].

Рефлексивность развивается (Ю.В. Громыко, В.В. Давыдов, А.В. Карпов, Н.Л. Романенко, И.Н. Семенов, С.Ю. Степанов, П.Г. Щедровицкий и другие) при наличии ситуации группового диалогового взаимодействия; проблемности задач; актуализирующих мотивацию взаимодействия; преодоления трудностей; достижения успеха; самоопределения и саморазвития.

Таким образом, в значительной части научных исследований представляются эмпирические характеристики студентов с разным уровнем рефлексивности. Рефлексивность рассматривается в связи с самопознанием, представлениями о себе как о субъекте своей будущей профессии, системой ценностей, половой дифференциацией, уровнем образования, успешностью обучения и решением интеллектуальных задач, успеваемостью, самораскрытием, когнитивными особенностями, характером межличностных отношений, подверженностью информационно-психологическому воздействию, адаптированностью к социальной микросреде, способностью принимать решение, психологическим здоровьем и другим.

Мы предположили, что к особенностям рефлексивности студентов педагогического профиля относятся наиболее выраженные временные виды рефлексивности, а также у низко- и высокотревожных студентов существуют значительные различия в латентной структуре рефлексивности.
За рабочее определение рефлексивности мы приняли точку зрения А.В. Карпова, Д.А. Леонтьева, представивших рефлексивность как личностное образование, свойство сознания, результат осмысления своей жизнедеятельности. «Рефлексия - способность человека произвольно обращать сознание на самого себя». «Рефлексивность - качественно особое свойство индивида, обеспечивающее осознание чего-либо и репрезентацию психике своего собственного содержания». Рефлексивность как модус рефлексии имеет степень выраженности и включенности субъекта в деятельность, объединяет коммуникативные, когнитивные и регулятивные процессы.

А.В. Карпов выделяет два вида рефлексивности по критерию направленности на объект и три вида рефлексивности по критерию временной направленности. По критерию направленности на объект выделены А.В. Карповым следующие виды рефлексии. «Интрапсихологическая рефлексия как способность к самовосприятию содержания своей собственной психики и его анализу, а также к анализу собственной деятельности. Интерпсихическая рефлексия - это способность к пониманию психики других людей, а также анализу общения, которая наряду с рефлексивностью как умением «встать на место другого» включает механизмы проекции, идентификации, эмпатии» [7].

По критерию временной направленности А.В. Карпов выделяет ситуативную, ретроспективную, перспективную рефлексии. К функции ситуативной рефлексии автор относит обеспечение самоконтроля за поведением человека в значимой ситуации, анализ происходящего в данный момент, соотнесение своих действий с конкретной ситуацией, их координации с изменяющимися условиями и собственным состоянием.

Ретроспективная рефлексия отражается в склонности к анализу реализованной в прошлом деятельности и свершившихся событий. Проявляется такая рефлексия в предикторах, мотивах произошедшего; содержание исполненного поведения, его результаты, последствия ошибки. Важным показателем ретроспективной рефлексии является частота и длительность протекания анализа и оценивания произошедших событий или наличие склонности к анализу прошлое и себя в нем. Перспективная рефлексия (рассмотрение будущей деятельности) выполняет функцию анализа предстоящей деятельности и поведения, планирования, прогнозирования возможных исходов. К поведенческим характеристикам перспективной рефлексии относится: тщательность планирования деталей своего поведения, частота направленности к будущим событиям, ориентация на них.

Д.А. Леонтьев и Е.Н. Осин выделяют четыре вида рефлексии по критерию направленности сознания: 
«арефлексия (полное отсутствие самоконтроля, сосредоточенность на внешнем интенциональном объекте деятельности)»; «интроспекция (самокопание) - сосредоточенность на собственном состоянии, собственных переживаниях»; «системная рефлексия - способность к самодистанцированию и взгляду на себя со стороны, позволяющая охватить одновременно полюс субъекта и полюс объекта»; «квазирефлексия - сосредоточенность на объекте, который не имеет отношения к актуальной жизненной ситуации, связанная с отрывом от актуальной ситуации бытия в мире» [9].

Эти типы рефлексии, как уточняет В.А. Чернов взаимосвязаны и взаимодополняют ее компоненты в структуре рефлексивности как личностного свойства. В зависимости от выраженности того или иного компонента можно говорить о преимущественной временной и объектной направленности рефлексивных процессов (на прошлое - настоящее - будущее, на себя - деятельность - общение), а с другой стороны, - о качестве этих процессов, и соответственно, - о положительной или отрицательной роли рефлексивности в деятельности и взаимодействиях [17].

В исследовании особенностей рефлексивности студентов принимали участие 92 респондента: студентыдевушки дневной формы обучения (бакалавриат, педагогический профиль), обучающиеся в ФГБОУ «Брянский государственный университет имени академика И.Г. Петровского». Средний возраст 19,5 лет, минимальный -17 лет, максимальный - 22 года.

Для реализации поставленных задач нами использованы следующие тестовые методы диагностического исследования рефлексивности студентов, апробированные в отечественной и зарубежной психологической практике: «Методика определения уровня рефлексивности» (А.В. Карпов, В.В. Пономарева); «Дифференциальный тип рефлексии» (Д.А. Леонтьев, Е.М. Лаптева, Е.Н.

\section{Осин, А.Ж. Салихова).}

Валидизация данных методов представлена авторами в публикациях и включением их в различные диссертационные исследования. Такое количество методик нам необходимо для описания разных показателей тревожности и рефлексивности, получения надежных и достоверных результатов.

Мы вычислили базовые количественные показатели рефлексивности по ее видам и уровню в целой выборке (табл. 1).

Среднее значение интегрального показателя рефлективности указывает на средний уровень рефлексивности у участников исследования и составляет 4 и 6 стенов, минимальное значение - 1 стен, максимальное - 8 стенов, медиана - 4 стена. Среди видов рефлексивности наиболее высокие значение отмечены по шкале «Рассмотрение будущей деятельности» с медианой 40 баллов, что выше среднего значения. По этой шкале данные имеют наибольший разброс (мин -19, макс-51) и наибольшее стандартное отклонение 7.1.

Полученные средние значения по шкалам «ретроспективная рефлексивность деятельности», рефлексивность настоящей деятельности», «рефлексивность общения и взаимодействия с другими людьми» указывают на умеренную выраженность этих видов рефлексивности в целой выборке.

Обращает на себя внимание шкала «системной рефлексии» со средними значениями 36.5 и стандартным отклонением 5,3, что выше результатов, полученных по шкалам «интроспекция» $(25,4)$ со стандартным отклонением 4,6; «квазирефлексия» $(26,5)$ со стандартным отклонением 4,7. Разброс данных вокруг средней по двум последним шкалам имеет примерно равные значения, они менее разбросаны относительно среднего значе-

Таблица 1

Статистические показатели рефлексивности у студентов педагогического профиля (по всей выборке)

\begin{tabular}{|l|c|c|c|c|c|}
\multicolumn{1}{|c|}{ Шкалы } & С & Медиана & Мин & Макс & С. откл \\
\hline Интегральный показатель рефлексивности & 4,6 & 4 & 1 & 8 & 1,8 \\
\hline Ретроспективная рефлексия деятельности & 35,5 & 36 & 22 & 47 & 5,8 \\
\hline Рефлексия настоящей деятельности & 35,6 & 35,5 & 23 & 49 & 5,8 \\
\hline Рассмотрение будущей деятельности & 39,1 & 40 & 19 & 55 & 7,1 \\
\hline Рефлексия общения и взаимодействия с другими людьми & 35,8 & 36 & 26 & 47 & 4,8 \\
\hline Системная рефлексия & 36,5 & 37 & 23 & 45 & 5,3 \\
\hline Интроспекция & 25,4 & 25 & 15 & 35 & 4,6 \\
\hline Квазирефлексия & 26,5 & 26 & 12 & 36 & 4,7 \\
\hline
\end{tabular}


ния в отличие от данных по шкале «системной рефлексии». Так, среди студентов есть участники исследования с очень высокими показателями системной рефлексии (45) относительно среднего.

Мы проанализировали результаты изучения уровня рефлексивности обучающихся с первого по четвертый курсы и сравнили данные с тестовыми нормами (табл.2). Полученные данные указывают на то, что низкий уровень рефлексивности отмечается у студентов первого курса (43\%), также как и у студентов третьего курса. На втором и четвертом курсах возрастает количество студентов с умеренным уровнем рефлексии. При этом у части студентов четвертого курса (19\%) рефлексивность достигает высокого уровня.

Интегральный показатель рефлексивности более высокий у студентов четвертого курса $(5,9)$. Исходя из тестовой нормы, эти обучающиеся склонны к анализу собственной деятельности и действий других людей. Они часто устанавливают причинно-следственные связи действий во временном отношении (прошлое, настоящее и будущее), Им свойственно обдумывание деталей деятельности, ее планирование и прогнозирование результатов. Выпускники чаще, чем студенты первых курсов могут понять и поставить себя на его место, предугадать его поведение.

Студенты первого курса менее всего способны к рефлексированию своих действий и поступков (низкие значения интегрального показателя рефлексивности). В сравнении с тестовой нормой (менее 4 стен) они в меньшей степени задумываются над собственной деятельностью, ее деталями, могут поставить себя на место другого человека.

Наибольшие значения фиксируются по шкалам «Ретроспективная рефлексия деятельности» (39.9), «Рефлек- сия настоящей деятельности» (41.9) у студентов четвертого курса. Для них характерно стремление к анализу прошлого опыта деятельности и состоявшихся событий, мотивов, причин, содержания, результатов прошлого поведения. Важное место в таком анализе занимают совершенные ошибки. Наблюдается тенденция к осмыслению собственного поведения в настоящем, самоконтролю деятельности.

Преобладающий вид рефлексии «Рассмотрение будущей деятельности» у студентов второго $(39,6)$, третьего $(38,4)$, четвертого курсов $(38,6)$ указывает на важность рассуждений о будущей деятельности, о ходе ее выполнения, планирования, о выборе способов выполнения, о прогнозировании исходов.

Данные, полученные по шкалам «Рефлексия настоящей деятельности», «Рефлексия общения и взаимодействия с другими людьми», указывают на умеренный уровень выраженности рефлексии этих видов у студентов-девушек, обучающихся по педагогическому профилю по всем курсам, кроме четвертого (описано выше). Можно предположить, что у студентов четвертого курса в ходе обучения сформированы умения осмысления и анализ происходящего, способность к проектированию, кооперации, коордированности взаимодействия участников деятельности на достаточно высоком уровне.

Системная рефлексия ярко представлена у студентов первого $(39,0)$, второго $(38,4)$ и четвертого $(38,6)$ курсов и менее всего - третьего $(30,9)$ и более всего выражена у обучающихся первого курса. Они склонны анализировать происходящее, разворачивать процесс принятия решения, в их поведение ярко проявляется склонность к самоанализу в конкретных жизненных ситуациях. Интроспекция и квазирефлексия не характерны для студентов данной выборки и показатели по этим шкалам отличаются низкими значениями.

Выраженность видов рефлексии у студентов разных курсов (в баллах)

\begin{tabular}{|c|c|c|c|c|}
\hline \multirow{2}{*}{$\begin{array}{c}\text { Вид } \\
\text { Рефлексии }\end{array}$} & \multicolumn{4}{|c|}{ Среднее значение рефлексии по курсам } \\
\hline & 1 курс & 2 курс & 3 курс & 4 курс \\
\hline Интегральный показатель рефлексивности & 3,5 & 4,8 & 3,9 & 5,9 \\
\hline Ретроспективная рефлексия деятельности & 33,3 & 36,4 & 32,5 & 39,9 \\
\hline Рефлексия настоящей деятельности & 35,8 & 35,6 & 32,9 & 38.4 \\
\hline Рассмотрение будущей деятельности & 35,2 & 39,6 & 39,1 & 41,9 \\
\hline Рефлексия общения и взаимодействия с другими людьми & 35,9 & 36,4 & 33,5 & 37,4 \\
\hline Системная рефлексия & 39,0 & 38,4 & 30,9 & 38,6 \\
\hline Интроспекция & 25,7 & 23,7 & 24,2 & 27,8 \\
\hline Квазирефлексия & 25,1 & 27,4 & 24,9 & 28,4 \\
\hline
\end{tabular}


Проверим достоверность различий в проявлениях разных видов рефлексии у студентов 1-4 курсов, использовав U-критерий Манна-Уитни (табл. 3).

На основе анализа данных таблицы 3 можем выделить значимые различия в уровне рефлексивности у студентов.

Студентов первого курса характеризует значимо отличный от третьего курса $(0,001)$ высокий уровень системной рефлексии. И наименее выраженные показатели по интегральному показателю (в сравнении со вторым $(0,018)$ и четвертым курсом $(0,001))$, по ретроспективной рефлексией деятельности (значимо отличны от показателей четвертого курса $(0,001))$, рефлексии будущей деятельности (выражены различия с третьим $(0,043)$ и четвертым курсом $(0,013))$.

Обучающиеся второго курса демонстрируют наименьшие показатели по уровню рефлексивности $(0,026$ - с третьим курсом, 0,035- с четвертым), ретроспективной рефлексией деятельности (0,011- с третьим курсом, 0,005- с четвертым), интроспекции (в сравнении с четвертым курсом $(0,003))$, системной рефлексии $(0,001)$, рефлексии общения и взаимодействия с другими людьми $(0,027)$ (отличные данные от третьего курса).

У студентов третьего курса значимые наименьшие значения в сравнении четвертым курсом, за исключением данных по шкале рефлексии будущей деятельности (нет различия).

На четвертом, завершающем, курсе для студентов характерно достоверные различия высоких значения в сравнении с третьим курсом во всем шкалам (кроме рефлексии будущей деятельности), с первым и вторым курсом - по уровню рефлексивности, ретроспективной рефлексии деятельности, с первым курсом - по рассмотрению будущей деятельности, со вторым курсом - по интроспекции.

У студентов первого и третьего курсов рефлексивность находится на низком уровне. Студенты первого курса менее всего способны к рефлексированию своих действий и поступков (низкие значения интегрального показателя рефлексивности). На втором и четвертом курсах возрастает количество студентов с умеренным уровнем рефлексии. Интегральный показатель рефлексивности более высокий у студентов четвертого курса. У студентов четвертого курса наибольшие значения фиксируются по шкалам «Ретроспективная рефлексия деятельности», «Рефлексия настоящей деятельности», «Рассмотрение будущей деятельности»» У студентов второго, третьего курсов преобладает рассмотрение будущей деятельности, что указывает на важность рассуждений о будущей деятельности, о ходе ее выполнения, планирования, о выборе способов выполнения, о прогнозировании исходов. Интроспекция и квазирефлексия не характерны для студентов данной выборки и показатели по этим шкалам отличаются низкими значениями. Обучающиеся второго курса демонстрируют наименьшие показатели по уровню рефлексивности, ретроспективной рефлексией деятельности, интроспекции, системной рефлексии, рефлексии общения и взаимодействия с другими людьми.

Таким образом, полученные эмпирические данные указывают у студентов-девушек, обучающихся по педагогическому профилю наиболее выражены рефлексивность, направленные на прошлое и будущее. Анализ происходящего в данный момент, соотнесение своих действий с конкретной ситуацией, их координации с из-

Таблица 3

Различия показателей рефлексии у студентов разных курсов по U-критерию Манна-Уитни (р)

\begin{tabular}{|l|c|c|c|c|c|c|c|c|}
\multicolumn{1}{r|}{ Вид рефлексии } & Ур & РРД & РНД & РБД & РО & СР & И & К \\
Курсы & & & & & & & & \\
\hline Первый/ второй & 0,018 & 0,082 & 0,820 & 0,068 & 0,930 & 0,432 & 0,106 & 0,124 \\
\hline Первый/третий & 0,399 & 0,637 & 0,079 & 0,043 & 0,139 & 0,001 & 0,367 & 0,864 \\
\hline Первый/четвертый & 0,001 & 0,001 & 0,164 & 0,013 & 0,615 & 0,615 & 0,147 & 0,057 \\
\hline Второй/третий & 0,026 & 0,011 & 0,090 & 0,622 & 0,027 & 0,001 & 0,524 & 0,065 \\
\hline Второй/четвертый & 0,035 & 0,005 & 0,167 & 0,321 & 0,591 & 0,545 & 0,003 & 0,331 \\
\hline Третий/четвертый & 0,001 & 0,001 & 0,001 & 0,145 & 0,003 & 0,001 & 0,013 & 0,009 \\
\hline
\end{tabular}

УР- уровень рефлексивности

РРД - Ретроспективная рефлексия деятельности

РНД - Рефлексия настоящей деятельности

РБД - Рассмотрение будущей деятельности
РО - Рефлексия общения и взаимодействия с другими людьми

СР - Системная рефлексия

И- Интроспекция

К - Квазирефлексия 
меняющимися условиями и собственным состоянием затруднен у будущих педагогов. Менее всего способны к рефлексированию своих действий и поступков студенты первого и третьего курсов. Однако обучающиеся первого курса вполне способны к анализу происходящего, разворачиванию процесс принятия решения, в их поведение ярко проявляется склонность к самоанализу в конкретных жизненных ситуациях. Студенты выпускных курсов более всего склонны к анализу собственной деятельности и действий других людей. Развитие оптимального уровня рефлексии временной направленности и системной рефлексии, направленной на сознание, будет способствовать формированию адекватного восприятия человеком ситуации.

\section{ЛИТЕРАТУРА}

1. Амосова Н.О. Рефлексивные механизмы сохранения психологического здоровья в студенческом возрасте// Педагогика и психология. Теория и методика обучения. С. 241-244. URL: https://cyberleninka.ru/article/n/refleksivnye-mehanizmy-sohraneniya-psihologicheskogo-zdorovya-v-studencheskom-vozraste (дата обращения 07.08.2019).

2. Волканевский С.В. Рефлексивность как детерминанта синдрома «психического выгорания» личности: Автореф. дис. ... канд. психол. наук. Ярославль, 2010. 26 c.

3. Дюпина С.А. Различия в запоминании бессмысленного материала при расщеплении полюсов когнитивного стиля «импульсивность/рефлексивность». URL: https://cyberleninka.ru/article/n/razlichiya-v-zapominanii-bessmyslennogo-materiala-studentami-pri-rasscheplenii-polyusov-kognitivnogo-stilyaimpulsivnost (дата обращения 11.08.2019).

4. Голубева Н.М. Особенности рефлексии в психологической адаптации студентов к образовательной среде организации высшего образования: Автореф. канд... дис. психол. наук. Саратов, 2018. С.18.

5. Зинник И.Н. Особенности структур интегральной индивидуальности студентов с различным уровнем развития рефлексивности// Вестник Ставропольского государственного университета Психологические науки. №54. 2008. С.59.

6. Каратеев 0.В. Исследование параметров объема и глубины самораскрытия у студентов с низким и высоким уровнем развития рефлексивности. URL: https://cyberleninka.ru/article/n/issledovanie-parametrov-obema-i-glubiny-samoraskrytiya-u-studentov-s-nizkim-i-vysokim-urovnem-razvitiya-refleksivnosti (дата обращения 06.07.2019)

7. Карпов А.В. Психология рефлексивных механизмов в деятельности. - М.: ИП РАН, 2004. С.362.

8. Карпов А.В., Скитяева И.М. Психология рефлексии/ Институт психологии РАН. Москва. Ярославль, 2001. 203 с.

9. Леонтьев Д.А., Осин Е.Н. Рефлексия «хорошая» и «дурная»: от объяснительной модели к дифференциальной диагностике // Психология. Журнал Высшей школы экономики. 2014. Т. 11. №4. С. 110-135.

10. Ляшук А.В. Оценка информационно-психологического воздействия на студентов с различным уровнем рефлексивности// Известия ЮФу. Технические науки. C.128. URL: https://socionet.ru/publication.xml?h=spz:cyberleninka:6258: 5837124 (дата обращения 07.09.2019)

11. Прохоров А.О., Чернов А.В. Влияние рефлексии на психические состояния студентов в процессе учебной деятельности// Экспериментальная психология. 2014. T. 7. № 2. C. $82-93$

12. Пьянкова Г.С. Рефлексия в структуре интернальной индивидуальности профессионала. Вестник КГПУ им. В.П. Астафьева. №6 Красноярск, 2010. С.70.

13. Самойличенко А.К., Токмакова А.А. Рефлексивность как психологический ресурс успешного обучения студентов ВПо (на примере студентов экономического профиля)// Азимут научных исследований: педагогика и психология. 2017. Т. 6. № 4(21). С. 374.

14. Санников А.И. Рефлексивность личности, принимающей решения// Universum: Психология и образование: электрон. научн. журн. 2014. № 11(10). URL: http://7universum.com/ru/psy/archive/item/1712 (дата обращения 11.10.2019).

15. Семенихина М.В. Психологические особенности рефлексии у мужчин и женщин// Вестник РГГУ. Серия «Психология. Педагогика. 0бразование». 2008. № 3. C. 63-79.

16. Филатова О.В. Рефлексивность как детерминанта деятельности исполнительского типа: Автореф. канд... дис. психол. наук. Ярославль, 2003. С.17.

17. Чернов А.В. Особенности взаимосвязи рефлексии и индивидуально-психологических особенностей личности студентов-психологов. URL: https://kpfu.ru/ staff_files/F690199160/Psihologiya.i.sovremennyj.mir.2012.pdf. (дата обращения 17.12.2019)

(с Бурыкина Марина Юрьевна (mabur03@yandex.ru).

Журнал «Современная наука: актуальные проблемы теории и практики» 